\title{
Comunicación Efectiva en Primer Curso de Grado en Ingeniería Biomédica
}

\author{
$\mathbf{M}^{\mathrm{a}}$ José Climent $^{\mathrm{a}}, \mathbf{M}^{\mathrm{a}}$ José Labrador $^{\mathrm{b}}$ e Isabel Morera ${ }^{\mathrm{a}}$ \\ GRUPO DE INNOVACIÓN E INVESTIGACIÓN EN METODOLOGÍAS ACTIVAS (GIIMA) \\ aDepartamento de Química, bepartamento de Lingüística Aplicada \\ Universitat Politècnica de València \\ Camino de Vera s/n. 46071-València \\ mjcliol@qim.upv.es, mlabrado@upvnet.upv.es, imorera@upvnet.upv.es
}

\begin{abstract}
One of the challenges facing higher education is to train professionals capable of adapting to the continuous changes of the society. Training should be directed towards the attainment of competences that include knowledge of materials, skills, attitudes and values that will enable them to adapt quickly, effectively and committed to the changes. In this scenario skills have a crucial role and should be developed within the framework of the subjects that constitute the curriculum. The Polytechnic University of Valencia has plans to incorporate thirteen of them into the curriculum of all its graduates. Competences are acquired from tasks that integrate all aspects that define them. This requires methodologies that promote active learning as well as the evaluation methods to demonstrate the achievements. In this communication, presented by several professors of the Grupo de Innovación e Investigación en Metodologías Activas (GIIMA), both the activities and the evaluation of the learning acquired by the students of two subjects in the first year of the degree of biomedical engineering related with the competence in "Effective communication", are described.
\end{abstract}

Keywords: cross-disciplinary skills, first course, effective communication, active learning.

\section{Resumen}

Uno de los retos a los que se enfrenta la Educación Superior es formar profesionales capaces de adaptarse a los cambios continuos de la sociedad actual. La formación debe orientarse hacia la consecución de competencias que incluyan los saberes de las materias, las habilidades, las actitudes y los valores que les permitan adaptarse de manera rápida, eficaz y comprometida 


\section{Comunicación Efectiva en Primer Curso de Grado en Ingeniería Biomédica}

a los cambios. En este escenario las competencias transversales tienen un papel fundamental y deben desarrollarse en el marco de las distintas materias que integran el plan de estudios. La Universitat Politècnica de València se ha planteado la incorporación de trece de ellas en el currículum de todos sus egresados. Las competencias se adquieren a partir de tareas que integren todos los aspectos que las definen, para ello se requiere de metodologías que promuevan el aprendizaje activo y de métodos de evaluación que acrediten la adquisición de las mismas. En esta comunicación, presentada por varios profesores de GRUPO DE INNOVACIÓN E INVESTIGACIÓN EN METODOLOGÍAS ACTIVAS (GIIMA), se describen las actividades desarrolladas y la evaluación del aprendizaje adquirido por los estudiantes de dos asignaturas de primer curso del Grado de Ingeniería Biomédica para la competencia transversal "Comunicación efectiva".

Palabras clave: competencias transversales, primer curso, comunicación efectiva, metodologías activas.

\section{Introducción}

La Universitat Politècnica de València (UPV) ha iniciado un ambicioso proyecto que pretende, entre otros objetivos, establecer una estrategia de evaluación sistemática de competencias transversales, definiendo dónde se adquieren y cómo deben ser evaluadas y acreditar la adquisición de las mismas para cada estudiante y para el conjunto de la promoción. Con el fin de sintetizar el perfil competencial que adquieren todos los estudiantes se aplicará en todos los títulos oficiales de Grado y de Máster que se imparten en la UPV. En el documento se recogen trece conceptos definidos en términos de competencias y se establecen diferentes niveles de dominio a alcanzar según se trate del título de Grado o de Master. Las Estructuras Responsables del Título (ERT) tienen el encargo de seleccionar las materias/asignaturas del título que constituirán los puntos de control de la adquisición de cada una de las competencias, y han de coordinar y realizar el seguimiento del grado de adquisisión de las mismas en base a las evidencias recogidas y los resultados obtenidos. De entre las competencias seleccionadas se incluye Comunicación efectiva.

Las competencias se demuestran en la acción y se aprenden y se desarrollan a partir de actividades que integren todos los aspectos que las definen (Brown, 2013). En este contexto los profesores del GIIMA que impartimos docencia en el Grado en Ingeniería Biomédica (GIB) nos hemos propuesto incorporar estrategias metodológicas, tecnológicas y

(cc) EY-NC-ND 2015, Universitat Politècnica de València 
evaluativas que influyan positivamente en el aprendizaje eficaz y que permitan la adquisición de dicha competencia en primer curso del GIB.

Partiendo de la experiencia previa del grupo (Varios autores, 2008) que ha demostrado en sus investigaciones (GIIMA, 2010; 2011; 2012; 2014) que las metodologías activas son una herramienta eficaz (Fernández, 2006) para que el estudiante adquiera no sólo conocimientos sino también diferentes habilidades sociales nos hemos centrado en el marco de las asignaturas El papel del Ingeniero Biomédico y Química que se imparten en primer curso de la titulación de GIB. Se describen los detalles de las actividades llevadas a cabo, los de su implementación y los resultados obtenidos durante el curso actual, así como la evaluación del aprendizaje adquirido por los estudiantes.

\section{Objetivos}

El objetivo general es afianzar en los estudiantes de primer curso del Grado de Ingeniería Biomédica, la integración de saberes, habilidades y valores mediante el desarrollo de la competencia transversal Comunicación efectiva. Para ello nos hemos propuesto los siguientes objetivos específicos:

- Identificar el nivel de partida de los estudiantes respecto a la competencia indicada.

- Diseñar tareas integradas orientadas al aprendizaje y desarrollo de la misma.

- Promover el uso de tecnologías de la información y la comunicación que contribuyan en el desarrollo de esta competencia.

- Coordinar las actividades con otros profesores de primer curso que incidan en la misma competencia.

- Evaluar mediante instrumentos adecuados el grado de adquisición de la competencia.

- Divulgar la experiencia adquirida para dinamizar su uso en otras asignaturas en el entorno universitario.

\section{Desarrollo de la innovación}

La acción se centra, como ya hemos señalado, en dos asignaturas de primer curso del título de GIB, y se ha llevado a cabo coordinadamente por las profesoras del GIIMA que impartimos docencia en el título. La muestra la constituyen los 80 estudiantes matriculados en primero del actual curso académico. 


\section{Comunicación Efectiva en Primer Curso de Grado en Ingeniería Biomédica}

El GIB se inició en el curso 2012-2013 y se desarrolla conjuntamente en la Escuela Técnica Superior de Ingenieros Industriales (ETSII) de la UPV y en la Facultad de Medicina de la Universitat de València.

La asignatura El papel del Ingeniero Biomédico se imparte en el primer cuatrimestre, tiene asignados 4,5 créditos, y tiene como objetivo dotar a los estudiantes de una visión global de lo que van a ser sus estudios, se centra en la formación transversal útil para su práctica académica y su futuro ejercicio profesional. Se imparte por profesorado especializado en cada uno de los temas, entre ellos Competencias comunicativas, que es impartido por una profesora del Departamento de Lingüística Aplicada, coautora de esta comunicación. Se trabajan los conceptos básicos sobre comunicación eficaz y se llevan a cabo actividades que permiten analizar textos reales y aprender a través del error. Se realizan tareas presenciales individuales y en grupo; se evalúa el orden lógico del discurso, la ortografía y el cierre del texto. Finalmente, se recoge la opinión del alumno mediante un texto de elaboración libre a partir de la definición del Instituto Cervantes de competencia comunicativa.

La asignatura Química es de formación básica, se imparte en el segundo cuatrimestre y tiene asignados 6 créditos. La primera parte de la asignatura (3 créditos) se dedica al estudio de conceptos relacionados con la Química Inorgánica, mientras que la segunda a conceptos de Química Orgánica, siempre relacionados con las aplicaciones bioquímicas. Aunque la mayoría de los estudiantes tienen conocimientos previos de Química, se trata de un grupo de perfil heterogéneo: médico, ingenieril y biotecnológico. La Química Orgánica es impartida por dos profesoras del Departamento de Química, coautoras de esta comunicación.

En esta asignatura se lleva a cabo, entre otras, una actividad de trabajo en equipo basada en el aprendizaje entre iguales y cooperativo, con el fin de integrar el aprendizaje de los conceptos químicos y a la vez desarrollar y evaluar la competencia transversal Comunicación efectiva teniendo en cuenta los siguientes aspectos:

El nivel previo de partida de los estudiantes: los estudiantes tienen cierta experiencia sobre la realización de exposiciones en equipo en la educación secundaria y bachillerato.

- $\quad$ El contexto en el que se desarrollará y evaluará la competencia: los estudiantes han de adquirir las competencias específicas de la asignatura y la competencia transversal de comunicación efectiva con un nivel de dominio básico.

La tarea consiste en el diseño en equipo de una presentación y exposición de un trabajo monográfico sobre las aplicaciones industriales y biomédicas de los compuestos de una determinada familia de compuestos orgánicos.

(c)) EY-NC-ND 2015, Universitat Politècnica de València 
Se han constituido 16 equipos de entre 4 y 6 miembros. Cada equipo prepara y expone un tema diferente. El profesor proporciona el material del que han de extraer y resumir la información más relevante para diseñar la presentación que exponen públicamente en clase en un tiempo determinado. Con el fin de garantizar la adquisición de la competencia con un nivel acorde al curso académico, se programa la tarea pautada, guiada y supervisada por el profesor en diferentes momentos del proceso de elaboración del producto final. En la Tabla 1 se muestran las actividades de enseñanza-aprendizaje diseñadas y el método de evaluación seguido.

Tabla 1. Actividades de enseñanza-aprendizaje y evaluación

\begin{tabular}{|c|c|}
\hline $\begin{array}{l}\text { Actividades de enseñanza- } \\
\text { aprendizaje }\end{array}$ & Actividades de evaluación \\
\hline $\begin{array}{l}\text { Elaboración por parte del profesor de un } \\
\text { documento con todos los detalles de la } \\
\text { tarea. }\end{array}$ & 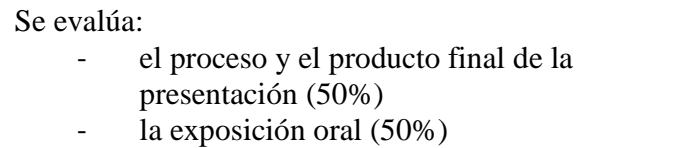 \\
\hline $\begin{array}{l}\text { Reunión del equipo para decidir cómo } \\
\text { distribuir el trabajo individual de cada } \\
\text { miembro del equipo }\end{array}$ & $\begin{array}{l}\text { El proceso: el profesor realiza un seguimiento de la } \\
\text { tarea, con plazos de entrega marcados, con el fin de }\end{array}$ \\
\hline $\begin{array}{l}\text { Trabajo individual de cada miembro del } \\
\text { equipo: elaboración del resumen del } \\
\text { contenido del material suministrado por } \\
\text { el profesor, diseño de la presentación y }\end{array}$ & $\begin{array}{l}\text { sobre la marcha del trabajo. Se programan tutorías a } \\
\text { las que acuden todos los estudiantes para revisar la } \\
\text { tarea con el profesor. }\end{array}$ \\
\hline $\begin{array}{l}\text { búsqueda de imágenes ilustrativas del } \\
\text { tema, etc. }\end{array}$ & $\begin{array}{l}\text { Se avalúa el cumplimiento con: la tarea individual, } \\
\text { las entregas en fecha, la actualización de las } \\
\text { propuestas de mejora en el trabajo. Herramientas de }\end{array}$ \\
\hline $\begin{array}{l}\text { Reunión del equipo para integrar los } \\
\text { contenidos individuales de cada }\end{array}$ & evaluación: observación y rúbrica. \\
\hline $\begin{array}{l}\text { miembro: participación activa de todos } \\
\text { los estudiantes en el diseño del producto } \\
\text { final. }\end{array}$ & $\begin{array}{l}\text { El producto final: se evalúa el aspecto formal y el } \\
\text { rigor de los contenidos. Herramientas de evaluación: } \\
\text { observación y rúbrica }\end{array}$ \\
\hline Supervisión del profesor del producto & La exposición oral: la evalúa el profesor. \\
\hline $\begin{array}{l}\text { elaborado y realización de las } \\
\text { propuestas de mejora. Se realiza dos }\end{array}$ & Herramienta de evaluación: rúbrica. \\
\hline revisiones, y una tercera, si procede & La nota se asigna por equipo. \\
\hline $\begin{array}{l}\text { Exposición del trabajo en la clase por } \\
\text { todos los miembros del equipo. }\end{array}$ & $\begin{array}{l}\text { ESTA TAREA COMPUTA } 10 \% \text { DEL TOTAL } \\
\text { DE LA NOTA FINAL }\end{array}$ \\
\hline
\end{tabular}

Así pues, durante el primer semestre se profundiza en la comunicación escrita y se dan unas primeras pautas para la comunicación oral; en el segundo, se aplican los conceptos

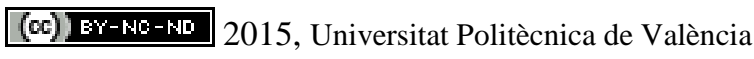

Congreso In-Red (2015) 


\section{Comunicación Efectiva en Primer Curso de Grado en Ingeniería Biomédica}

aprendidos sobre la comunicación escrita y oral y se evalúa el progreso del alumno desde su inicio hasta el final del curso.

Herramientas de recogida de datos:

- Trabajos escritos por los estudiantes que son analizados cualitativamente.

- Cuestionario de reflexión del estudiante sobre la experiencia llevada a cabo y la formación de los estudiantes en la competencia comunicativa escrita y oral, que se analiza cuantitativamante.

- Rúbrica para valorar cuantitativamente el proceso de preparación de la presentación, el producto final y la exposición oral llevada a cabo por cada uno de los miembros del equipo.

- Observación no participante a través de una ficha de observación con el fin de que los observadores valoren los mismos aspectos.

- Grabaciones en vídeo de las exposiciones en el aula para su posterior análisis.

Debido a la cantidad de información recogida presentamos a continuación los datos más relevantes.

\section{Resultados}

Las manifestaciones de los alumnos, en el primer cuatrimestre, se recogen en la figura 1 agrupadas por conceptos:

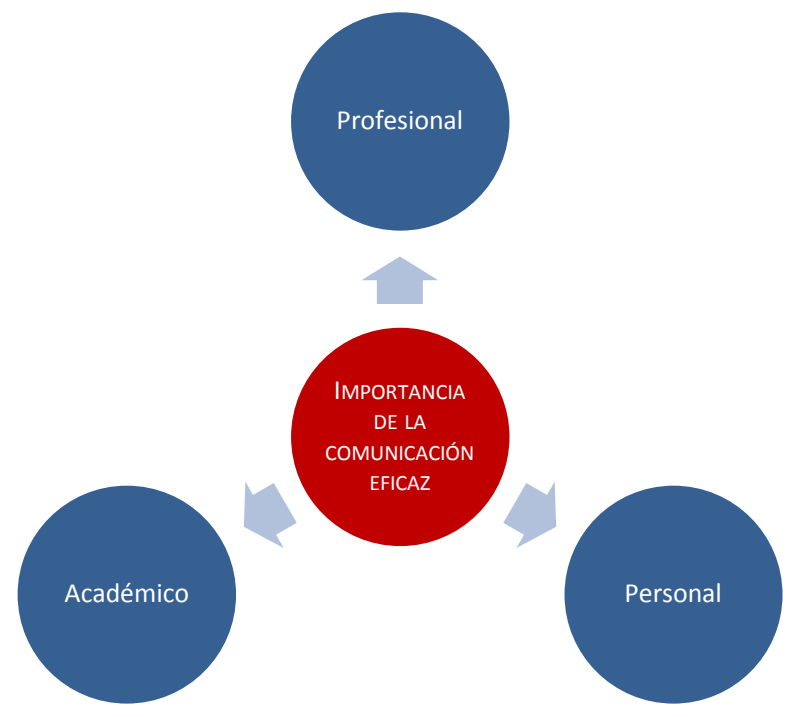

Fig. 1 Ámbitos en los que consideran importante la competencia comunicativa

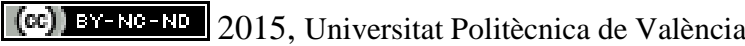

Congreso IN-RED (2015) 
Citamos literalmente algunas de las opiniones referentes al ámbito profesional:

«La competencia comunicativa es especialmente importante en las ingenierías donde tenemos que presentar proyectos e informes», «La capacidad comunicativa es una de las herramientas más importantes para tener éxito», «La competencia comunicativa es uno de los aspectos que más valoran las empresas», «Es importante tanto en el ámbito diario como en el laboral», «Es importante perfeccionarla para el futuro profesional», «Para un discurso profesional es necesario un léxico rico y variado», «La forma de expresarnos determina cuál va a ser nuestro fututo», «Es necesario el dominio de ambas capacidades, oral y escrita, en el día a día de un profesional», etc.

Respecto al ámbito académico manifiestan:

«Un buen proyecto no capta inversores si no se expone bien», «La habilidad de comunicar tiene un papel crucial en nuestra vida académica y laboral», «La práctica de la expresión oral proporciona tranquilidad, dominio sobre el tema y dominio sobre la propia persona», «una buena presentación es importante para c aptar la atención», «Es importante una buena conclusión puesto que las últimas palabras son las que mejor suelen recordarse», «Un buen estudiante deja de serlo cuando, a pesar de sus conocimientos, no es capaz de expresarlos adecuadamente», «Un texto bien estructurado tiene que seguir una serie de reglas», etc.

En lo que se refiere al ámbito personal expresan:

«Es una habilidad que toda persona tendría que tener», «Saber hablar bien es una habilidad compleja y necesaria», «No es sencillo comunicarnos eficientemente», «Incluso cuando vamos a hacer una compra debemos hacer un uso correcto de la lengua», «En nuestro día a día necesitamos hacernos entender, así como también necesitamos entender a los demás», «Es fundamental una buena competencia comunicativa de los miembros de una sociedad para un correcto entendimiento, funcionamiento y progreso de dicha sociedad», etc.

En la figura 2 reune los aspectos que, según opinión del alumnado, se han de cuidar para lograr una buena competencia comunicativa.

Citamos las afirmaciones más relevantes:

«El lenguaje no verbal representa un porcentaje muy elevado de la expresión oral, por tanto, hemos de cuidar los movimientos, y posturas», «En una exposición oral hay que cuidar el tono de voz y el énfasis que variará en función de lo que se esté diciendo en cada momento», «El desarrollo, la preparación, el entorno... son fundamentales en una presentación oral», «La preparación es imprescindible para una buena presentación», «Hablar y escribir que en principio parece "poca cosa” o que ya sabemos desde pequeños es algo necesario en nuestros días y por tanto hay que ir preparándonos poco a poco», «Mis presentaciones suelen contener únicamente imágenes con los conceptos que voy a tratar, de

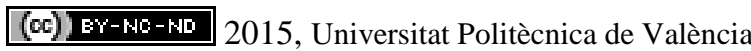




\section{Comunicación Efectiva en Primer Curso de Grado en Ingeniería Biomédica}

esta forma capto el interés», «Practicar, practicar, practicar cuantas veces sea necesario es importante para exponer bien», etc.

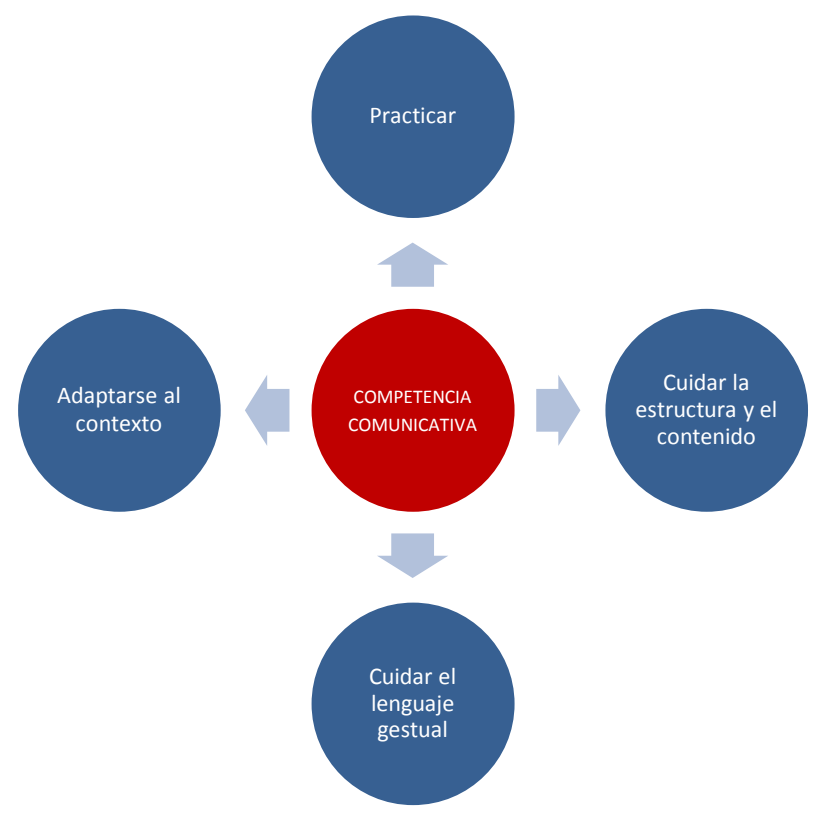

Fig. 2 Aspectos importantes en la competencia comunicativa

Los resultados más relevantes del segundo cuatrimestre, se muestran en la Tabla 2, recogen datos respecto al aspecto formal, la selección, el resumen y el rigor de los contenidos incluidos en la primera versión de la presentación, que los equipos han entregado al profesor para que este la supervise y les proponga las mejoras pertinentes.

El análisis de los resultados relativos al aspecto formal permite afirmar que:

- Un aspecto tan básico como es citar los autores que elaboran la presentación, tan solo es aportado por el $60 \%$ de los equipos, que lo hace correctamente por orden alfabético de apellidos; el resto lo omite o bien los ordena aleatoriamente o por orden alfabético de los nombres.

- $\quad$ La mayoría diseñan la presentación con un aspecto visual correcto (80\%).

- Aproximadamente el $90 \%$ de los equipos no incluyen un índice completo (introducción, desarrollo, conclusiones y bibliografía), destacando la mayoría de las veces la omisión de la introducción, las conclusiones y la bibliografía.

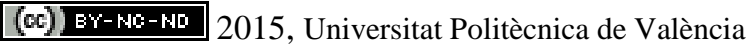


- Sólo alrededor del 10\% incluye y cita la bibliografía atendiendo a norma.

- $\quad$ Un porcentaje muy elevado omite citar los datos de la asignatura.

Tabla 2. Porcentaje de equipos que incluyen la información requerida en la primera versión de la presentación

\begin{tabular}{|c|c|c|}
\hline \multicolumn{2}{|r|}{ Aspectos a valorar } & $\%$ de equipos que los incluyen \\
\hline \multirow{6}{*}{ Estructura } & Autores por orden alfabético & 60 \\
\hline & Datos de la asignatura & $10-15$ \\
\hline & Índice completo & 13 \\
\hline & Conclusiones & 10 \\
\hline & Bibliografía & 10 \\
\hline & Diseño: visualización, color y uniformidad & 80 \\
\hline \multirow{4}{*}{ Contenido } & Se adapta a la propuesta & 47 \\
\hline & Resumen & 27 \\
\hline & Incluye figuras & 100 \\
\hline & Se aportan datos que enriquecen el trabajo & 7 \\
\hline
\end{tabular}

Respecto al contenido, los datos evidencian que :

- Sólo el 50\% de los equipos se adaptan a la propuesta que sobre el contenido del tema les han planteado los profesores, lo cual hace pensar que no han leído el documento con los detalles de la tarea que deben desarrollar.

- $\quad$ Unicamente el 27 \% son capaces de resumir correctamente el contenido y plasmar las ideas principales en la presentación.

- Todos incluyen figuras pero la mayoría (80\%) no aportan la correspondiente leyenda.

- $\quad$ El 7\% aporta contenidos que enriquecen el contenido del texto.

Es de resaltar que el 80\% de los equipos actualizan entre el 50 y $90 \%$ de las propuestas de mejora de la primera versión para la entrega de la segunda. Por tanto, se requiere de una 


\section{Comunicación Efectiva en Primer Curso de Grado en Ingeniería Biomédica}

nueva revisión que originará la tercera versión del producto final, que no en todos los casos llega a tener el nivel de calidad óptimo.

Con respecto a la exposición oral llevada a cabo por todos los miembros de los equipos se destaca la habilidad de la mayoría de ellos. Esto confirma que el nivel de adquisición de la competencia comunicativa oral es notable.

\section{Conclusiones}

Este trabajo nos ha permitido recoger la información necesaria sobre el desarrollo y la integración de conocimientos y habilidades, obtener una retroalimentación sobre el proceso de adquisición de la competencia, para optimizar el planteamiento de las tareas, reorientar, adaptar y difundir los resultados a otros docentes para que sirvan de orientación en el desarrollo de competencias.

De los datos obtenidos se desprende que como en Secundaria y Bachillerato ya realizan trabajos académicos escritos y exposiciones orales los alumnos se creen preparados y olvidan que en la universidad tienen que abordar una escritura académica más compleja como redactar memorias e informes técnicos, diseñar presentaciones, etc. que requieren conocimientos específicos. Contrasta la dificultad que muestran para seleccionar la información relevante y resumirla y diseñar una presentación clara y acorde al contenido, con su notable desempeño en la exposición oral.

El dato más sorprendente ha sido comprobar que a pesar de manifestar lo importante que es una comunicación efectiva, tanto en el mundo profesional como en el académico, la mayoría no considera necesario una formación específica.

Todo ello, nos lleva aconcluir que todavía hay un largo camino por recorrer para alcanzar el mínimo exigido en un entorno universitario y en el ámbito profesional futuro. Esto implica realizar actividades que desarrollen diferentes capacidades básicas (como la capacidad de síntesis), insistir constantemente en que sigan las pautas de los docentes y revisen los conocimientos desarrollados en el primer cuatrimestre sobre el índice, la estructura, las referencias bibliográficas, el diseño, etc. o bien se plantee la necesidad de aumentar el número de horas de impartición.

Finalmente, consideramos que a pesar del enorme trabajo coordinado realizado por los profesores de estas dos asignaturas, no ha sido suficiente para conseguir unos resultados óptimos y estimamos que debería haber una estrecha colaboración entre todos los profesores que imparten docencia en primer curso para alcanzar un nivel razonabable en la competencia Comunicación efectiva. 
$M^{a}$ José Climent, $M^{a}$ José Labrador e Isabel Morera

\section{Bibliografía}

BROWN, S. Y PICKFORD, R. (2013). Evaluación de habilidades y competencias en Educación Superior. Madrid: Narcea, S.A. Ediciones.

Fernández, A. (2006). "Metodologías activas para la formación de competencias” en Educatio Siglo $X X I, 24$, pp. $35-56$.

GIIMA. (2010). "Motivación en el aula y disminución del abandono de asignaturas en primer curso mediante la implementación de metodologías activas” Proyecto PIME A008/10. Curso 2010-11. Vicerrectorado de Estudios y Convergencia Europea (VECE). UPV.

GIIMA (2011). “La reflexión en la acción. Un estudio de análisis y de mejora metodológica en las aulas de primer curso de ingeniería”. Proyecto PIME A24/11. Curso 2011-12. Vicerrectorado de Estudios y Convergencia Europea (VECE). UPV.

GIIMA (2012). "Práctica reflexiva e implicación metodológica. Un estudio en las aulas de primer curso de ingeniería". Proyecto PIME A18/12. Curso 2012-13. Vicerrectorado de Estudios y Convergencia Europea (VECE). UPV.

GIIMA (2014). “Análisis de la implementación y evaluación de las competencias transversales en los primeros cursos de ingeniería”. Proyecto PIME A020/14. Cursos 2014-16. Vicerrectorado de Estudios y Convergencia Europea (VECE). UPV.

VARIOS AUTORES. (2008). Metodologías activas. GIMA. Editoras: $\mathrm{M}^{\mathrm{a}}$ José Labrador y $\mathrm{M}^{\mathrm{a}}$ Ángeles Andreu. Valencia: Universitat Politècnica de València.

(cc)) EY-NC-ND 2015, Universitat Politècnica de València

Congreso In-Red (2015) 